\title{
A quatro mãos: o processo de co-construção de sentidos no jogo entre a notícia e o leitor.
}

Thalita Sasse Fróes *

\begin{abstract}
Resumo
O artigo observa a produção de sentidos, através do jogo interacional entre o leitor e a notícia, manifesto durante o ato de leitura. A notícia não mais entendida como a verdade absoluta de um relato neutro, mas sim como uma das possíveis distinções da realidade multiversa realizada pelo jornalista insere o leitor como parte ativa da negociação e da atualização dos significados em um processo de co-construção da realidade social.
\end{abstract}

\section{Introdução.}

$\mathrm{O}$ intuito deste artigo consiste em identificar o jornal como um importante interlocutor no diálogo estabelecido com o leitor durante $\mathrm{o}$ ato de leitura, de forma que o jogo interacional desenvolvido entre as intenções do jornalista, a materialidade do texto e as expectativas do leitor se atualizem periodicamente, tornando possível o processo de co-construção de sentidos. O jornalista enquanto co-construtor da realidade social confere à notícia a capacidade de organizar a práxis social através de narrativas consensualmente compartilhadas por uma sociedade Esta discussão se propõe a observar as notícias de jornais como produtos culturais, como formas narrativas de contar as histórias do mundo. Para tanto, tomar-se-ão como ponto de partida para entender a co-construção de sentidos pelo jornalismo as propostas de Paul Ricoeur e outros autores da teoria literária, ressalvando as particularidades da comunicação jornalística.

Sendo um meio de comunicação de massa, o jornal pode ser descrito como um veículo responsável pela publicação de informações periódicas. Imerso em uma infinidade de fatos cotidianos,

* Mestre em Comunicação pela Universidade de Brasília e professora da Faculdade de Comunicação Social e Biblioteconomia da Universidade Federal de Goiás.

Comun. Inf., v. 6, n. 1, p.73-86, jan./jun. 2003 
o jornalista assume o compromisso de selecionar certos acontecimentos e destacar de forma objetiva para o leitor eventos da realidade física e social. $\mathrm{O}$ caráter rotineiro e ritualístico do jornalismo confere à notícia uma contingência por vezes semelhante ao jogo presente no ato da leitura literária, o que torna pertinente uma aproximação entre alguns conceitos desenvolvidos por ambas. Ao tomar como base o ato de leitura literária tal como a descrevem alguns autores é possível perceber a aplicação de conceitos próprios da literatura ao jornalismo com intuito de observar o jogo interacional manifesto no encontro entre a notícia e o leitor. Sob esse prisma, conceitos como autor implicado, texto inacabado e leitor implicado se apresentam fundamentalmente importantes para a compreensão do processo de comunicação jornalística.

Baseado em uma teoria da leitura, com ênfase na própria resposta do leitor aos estratagemas do autor implicado, Ricoeur (1997) sugere a teoria da literatura menos voltada para retórica, e a aponta como oscilando entre uma fenomenologia ou uma hermenêutica. Isso porque a fenomenologia, ao definir como ponto de partida o aspecto inacabado do texto literário, ressalta o processo de co-construção dos sentidos, os quais jamais se consubstanciariam na ausência do leitor. Sendo assim, um texto inacabado pode ser descrito

"no sentido de que oferece diferentes "vistas esquemáticas", que o leitor é chamado a "concretizar"; por esse termo, deve-se entender a atividade figurante pela qual o leitor se empenha em se figurar os personagens e os acontecimentos relatados pelo texto; é relativamente a essa concretização figurante que a obra apresenta lacunas, "lugares de indeterminação"; por mais articuladas que sejam as "vistas esquemáticas" propostas à execução, o texto é suscetível de execuções diferentes. E ainda no sentido de que o mundo que ele propõe se define como o correlato intencional de uma sequência de frases, do qual falta fazer um todo, para que um tal mundo seja visado." (INGARDEN, 1974 apud RICOEUR, 1997: 287-288)

O leitor previsto pelo autor como capaz de cooperar para a atualização textual deve movimentar-se interpretativamente conforme o autor se movimentou para produzir o texto. $\mathrm{O}$ jogo de retenções e protensões do texto far-se-á presente à medida que o leitor aceitá-lo no jogo de suas próprias expectativas. É possível constatar que o mundo do texto assinala, então segundo Ricoeur(1997)

Comun. Inf., v. 6, n. 1, p.73-86, jan./jun. 2003 
a abertura do texto para o que está "fora" dele, para o seu "outro", na medida em que o mundo do texto constitui relativamente à estrutura "interna" do texto uma intenção absolutamente original. Mas deve-se ressaltar que considerado à parte da leitura, o mundo do texto continua sendo uma transcendência na imanência. Seu estatuto ontológico permanece em suspenso: em excesso relativamente à estrutura, à espera da leitura.

De forma semelhante, a notícia só se caracteriza como um processo de co-produção de sentidos a partir do momento em que o leitor decodifica seu conteúdo informativo e atualiza seus significados. Para tanto, o leitor responde à estratégia do autor acompanhando a configuração e apropriando-se da proposta do mundo do texto. Neste sentido, como afirma Paul Ricoeur (1997), de tanto procurar a "leitura no texto", uma escrita só se deixa interpretar em função das interpretações que ela abre; com isso a leitura por vir é a incógnita sobre a qual a escrita é perspectivada. A tríade formada pelo autor-texto-leitor configura o momento do ato de leitura; esta por sua vez faz parte do texto, está inscrita nele. A leitura já não é o que o texto prescreve; ela é o que revela a estrutura por meio de interpretação. É sob esse prisma que se torna justificável compreender o espaço intermediário da notícia como o local de manifestação do ato de leitura, onde a tríade jornalistanotícia-leitor se processa para produzir sentidos.

\section{O processo de mutação: 0 ato de leitura.}

Ao considerar o ato de leitura, autores como Paul Ricoeur, Umberto Eco e Wolfgang Iser trazem importantes postulados teóricos para a compreensão do processo de interação entre o texto e o leitor. Todavia torna-se pertinente salvaguardar as peculiaridades referentes ao âmbito tanto da literatura, quanto do jornalismo; isso porque não se trata aqui de considerar o jornalismo como uma atividade literária ao fazer uso dos conceitos de autor implicado, texto inacabado e leitor implicado. Mas sim de reconhecer o seu papel como um instrumento de uma construção fragmentada da realidade na qual seus leitores se encontram inseridos.

Sob esse prisma, ao referir-se ao processo de interação entre o texto e o leitor das narrativas literárias, Umberto Eco (2002) afirma que um texto postula o próprio leitọ como condição indispensável,

Comun. Inf., v. 6, n. 1, p.73-86, jan./jun. 2003 
não só da própria capacidade concreta de comunicação, mas também da própria potencialidade significativa. Assim como o autor entrega o texto ao leitor para que este o atualize, o jornalista entrega a notícia ao leitor do jornal. No entanto, ambos ao entregarem seus produtos ao jogo entre o mundo do texto e o mundo do leitor afastam-se do processo de interação, permitindo que apenas as marcas por eles deixadas no texto conduzam seus leitores às possibilidades de produção de sentidos.

Cabe ressaltar, contudo, uma diferença que quando melhor observada pode-se transformar em semelhança entre os contextos literário e jornalístico. A relação entre o autor e o leitor, a priori, parece sugerir uma postura diferente em ambos os contextos, uma vez que, enquanto para o autor literário a produção da obra não necessariamente implica na existência empírica do leitor, para o jornalista, ao contrário, a produção da notícia pressupõe a existência concreta e empírica do seu leitor. Tal postura jornalística pode ser facilmente inviabilizada ao se considerar o quinto critério de noticiabilidade descrito pela própria prática profissional, o valornotícia referente ao público, o qual se baseia na imagem que o jornalista tem do seu público, por si pode ser considerado controverso por consubstanciar-se em avaliações pessoais do jornalista ou dos órgãos de informação.

Nesta perspectiva, o jornalista assim como o autor literário entrega a notícia não a um leitor empírico, mas a um tipo de leitor pressuposto, o que U. Eco descreveu como leitor-modelo, W. Iser como leitor implícito e P. Ricoeur como leitor implicado. O leitormodelo constitui um conjunto de condições de êxito, textualmente estabelecidas que devem ser satisfeitas para que um texto seja plenamente atualizado no seu conteúdo potencial. U. Eco (2002) acrescenta que prever o leitor-modelo não significa somente "esperar" que ele exista, mas sim também mover o texto de modo a construí-lo; de forma capaz de perspectivar a competência sob a qual o texto repousará, o que não indica que o texto é entregue à onipotência do leitor, mas que ao mesmo tempo em que o texto pressupõe a competência necessária do leitor, de modo recursivo, acaba por direcioná-la.

Sendo assim, mais uma vez, é possível encontrar uma semelhança através de uma aparente diferença entre o jornalismo e a literatura. A forma como o autor se faz presente, explícita ou

Comun. Inf., v. 6, n. 1, p.73-86, jan./jun. 2003 
implicitamente, torna-se fundamentalmente relevante na tentativa de compreensão do jogo manifesto no ato de leitura. Isso por que ao tomar da literatura os conceitos de autor implicado descrito por Paul Ricoeur (1997) e autor-modelo de Umberto Eco (2002), esses podem ser facilmente utilizados na compreensão da postura do jornalista diante do seu produto-notícia. Ricoeur (1997) afirma que diante do texto o único tipo de autor cuja autoridade está em jogo não é o autor real, objeto de biografia, mas sim o autor implicado; ele é quem toma a iniciativa da prova de força que subjaz à relação da escritura com a leitura.

"Os procedimentos retóricos pelos quais o autor sacrifica a sua presença consistem precisamente em dissimular o artifício pela verossimilhança de uma história que parece contar-se sozinha e deixar falar a vida, que assim, é chamada de realidade social, comportamento individual ou fluxo de consciência.” (RICOEUR, 1997: 279)

Tais procedimentos, por sua vez, permitem ao jornalista assim como o autor literário outorgar à estória o poder de interlocução com o leitor. Neste sentido, o jornal funcionaria como a materialidade necessária para o diálogo com o mesmo, pois a fim de se fazer cumprir o compromisso com a verdade, o jornalista lança mão de sua presença explícita no texto e, por conseguinte, desempenha seu papel de co-construtor da realidade ao organizar a narrativa capaz de distinguir a verdade de uma realidade multiversa.

Ao considerar o conceito de autor implicado e leitor implicado, Ricoeur (1997) num primeiro momento estabelece uma simetria entre os termos, tendo cada um suas marcas do texto. Construídos no texto, são ambos correlatos ficcionalizados de seres reais: o autor implicado identifica-se com o estilo singular da obra; o leitor implicado, com o destinatário a que se dirige o destinador da obra. Contudo Ricoeur (1997) acrescenta que tal simetria se revela um pouco mais complexa, uma vez que o autor implicado consiste em um disfarce do autor real, que desaparece transformando-se em narrador imanente à obra - voz narrativa; e o leitor real é uma concretização do leitor implicado, visado pela estratégia de persuasão do narrador; relativamente, o leitor implicado permanece virtual enquanto não é

Comun. Inf., v. 6, n. 1, p.73-86, jan./jun. 2003 
atualizado. Assim, ao passo que o autor real se apaga no autor implicado, o leitor implicado ganha corpo no leitor real, onde procede a significação da obra.

Sob esse prisma, a descrição do conceito de autor-modelo de U. Eco vem corroborar os aspectos já postulados por Ricoeur (1997). Eco (2002) acrescenta que a configuração do autor-modelo depende de traços textuais, mas põe em jogo o universo do que está atrás do texto, atrás do destinatário e provavelmente diante do texto e do processo de cooperação, o qual não deve ser entendido como a atualização das intenções do sujeito empírico da enunciação, mas como as intenções virtualmente contidas no enunciado. Não obstante, ao fazer jus ao autor-modelo, torna-se pertinente considerar as circunstâncias de enunciação, não só para melhor compreendê-lo como também para possibilitar a inferência das intenções do sujeito empírico da enunciação, ao determinar a escolha de um autor-modelo.

\begin{abstract}
"Se de um lado, o autor empírico, enquanto sujeito da enunciação textual, formula uma hipótese de leitor-modelo e, ao traduzi-la em termos da própria estratégia, configura a si mesmo autor na qualidade de sujeito enunciado, em termos igualmente "estratégicos", como modo de operação textual. De outro lado também o leitor empírico, como sujeito concreto dos atos de cooperação, deve configurar para si uma hipótese de autor, deduzindo-a justamente dos dados de estratégia textual." (ECO, 2002:46)
\end{abstract}

$\mathrm{O}$ ato de leitura consiste em um processo recursivo onde autor, circunstâncias da enunciação, texto e leitor se influenciam mutuamente. Mesmo frente a um encadeamento temporal linear em que cada instância se faz presente, $o$ ato de leitura em si representa a confluência simultânea de todas elas. $O$ jornal pode, então, ser entendido como semelhante a um texto aberto, uma vez que assim como na literatura,

"o autor decide até que ponto deve controlar a cooperação do leitor e onde esta é provocada, para onde é dirigida, onde deve transformar-se em livre aventura interpretativa. Só uma coisa ele tentará com sagaz estratégia: que, por maior que seja o número de interpretações possíveis, uma ecoe a outra, de modo que não se excluam, mas antes, se reforcem mutuamente."(ECO, 2002: 42)

Comun. Inf., v. 6, n. 1, p.73-86, jan./jun. 2003 


\section{O local do ponto de mutação: o espaço intermediário.}

O espaço intermediário, consubstanciado entre o processo de produção e recepção do jornal, caracteriza-se como o local de interação entre o texto e o leitor. Sendo assim, ao comprar o jornal, o leitor estabelece com ele "um pacto de interlocução, justamente com o objetivo de enriquecer sua opinião e seu conhecimento dos fatos. Temer o leitor ou adular sua opinião é, paradoxalmente, contrariá-lo na relação que ele presume ter com o jornalismo" (MANUAL DE REDAÇÃO DA FOLHA DE S. PAULO, 2002: 23). Texto e leitor se apresentam pressupostamente exercendo papéis definidos; o primeiro, redigido com base nos cânones da profissão, assegura a clareza e a precisão do relato verossímil e o segundo, supostamente passivo, será capaz de decodificar toda informação recebida de acordo com a expectativa do jornalista.

A atividade presente no espaço intermediário não ocorre de maneira linear, de forma que a mensagem emitida através do texto seguramente corresponda à mensagem recebida pelo leitor. Ao contrário, é possível perceber um constante movimento de negociação entre os mesmos, capaz de proporcionar um número diverso de combinações e possibilidades de interpretação. Todavia tal aspecto não implica na caracterização desta atividade como desordenada ou alógica; isso porque o texto ao indicar diversas possibilidades e o leitor ao se constituir enquanto parte ativa do processo de interpretação são legitimados como capazes de conduzi-lo de forma coerente negociando a co-construção de sentidos.

Enquanto o texto jornalístico estrutura a informação como "o que é possível e o que é legitimo mostrar, mas também o que se deve saber, o que está marcado para ser percebido" (MOUILLAUD, 2002:38) o leitor dispõe de flexibilidade para conduzir a interpretação, não se sujeitando de forma passiva e ingênua às estruturas do texto. As estruturas pré-determinadas norteiam as possibilidades de interpretação, contudo a condução do processo, o resultado final e seus desdobramentos são competências do trabalho do leitor. Sob esse prisma, o jornal

"é apenas um operador entre um conjunto de operadores sócio-simbólicos, sendo, aparentemente, apenas o último: porque o sentido que leva aos leitores, estes, por sua vez, remanejam-no a partir de seu próprio campo mental e

Comun. Inf., v. 6, n. 1, p.73-86, jan./jun. 2003 
recolocam-no em circulação no ambiente cultural. Se, na origem, o acontecimento não existe como um dado de "fato", também não tem solução final. A informação não é o transporte de um fato, é um ciclo ininterrupto de transformações." (MOUILLAUD, 2002:51)

A notícia materializada no jornal impresso pelos textos escrito e icônico apresenta-se como o local de manifestação do espaço intermediário, onde será consubstanciado o encontro dos mesmos com o leitor. Sendo assim, a série de notícias a respeito de um mesmo assunto, uma vez encadeada, pode conferir uma sequência ao leitor semelhante à de uma narrativa. Os fatos, assim engrenados, sugerem o desenrolar de uma história composta por capítulos diários, sem, no entanto, comprometer o acordo tácito estabelecido entre o jornalista e o leitor, onde o texto escrito reafirma o compromisso com a verossimilhança ao relatar o fato de forma objetiva e o texto icônico ao representar a realidade.

Os textos, escrito e icônico, se apresentam como obra a ser decodificada pelo leitor; este por sua vez, frente ao "espelho do real", se coloca como capaz de transcender à própria obra. O "mundo do texto" se abre ao leitor com uma pluralidade de significados, cuja "coisa do texto" não mais pertence ao autor, pois já se encontra à disposição do que Ricoeur (1997) chamou de "mundos possíveis" do leitor. O autor, no jornalismo entendido como o jornalista que assina a matéria publicada ou a agência de notícias que a distribui, ao dispor de sua propriedade, entrega a obra ao jogo entre o mundo do texto e o do leitor, e a referência à realidade objetiva, pretensa a priori, sede espaço à produção de sentidos.

A leitura do jornal impresso, como hábito comum da sociedade atual, insere cotidianamente o leitor nesse jogo entre objetividade e suspensão da objetividade; isso porque, no processo de interação entre o texto e o leitor, o primeiro não se apresenta ao segundo de forma pronta e acabada, mas, ao contrário, convida-o a participar de um processo de produção de sentidos. Dessa forma, ao solicitar a iniciativa do leitor, o texto não mais se apresenta como um mero conjunto de informações, mas também como uma obra capaz de ser transcendida. O texto em si traz espaços onde serão realizados os movimentos do leitor, os quais apesar de norteados por estruturas pré-estabelecidas podem proporcionar uma pluralidade de sentidos produzidos; de acordo com Eco (2002) o texto se torna uma estrutura completa por estar

Comun. Inf., v. 6, n. 1, p.73-86, jan./jun. 2003 
entremeado pelo não-dito que significa não manifestado em superfície, no nível da expressão, mas é justamente esse não dito que tem de ser atualizado no nível do conteúdo. E para esse propósito um texto, de uma forma ainda mais decisiva do que qualquer outra mensagem, requer movimentos cooperativos, conscientes e ativos da parte do leitor.

Ao comprar o jornal, o leitor espera que este contenha as informações relevantes, relatadas com precisão, a respeito do que aconteceu nas últimas vinte e quatro horas; por outro lado a notícia, resultado de um trabalho que envolve um amplo processo de produção, apresenta-se como capaz de corresponder às expectativas do leitor em se manter informado. Entretanto a objetividade jornalística assegurada pelo contrato entre o jornalista e o leitor encontra-se permeada por aspectos capazes de corrompê-la, aspectos estes que vão desde a própria rotina de produção e edição à conduta profissional do jornalista. Sendo assim, a notícia não pode ser entendida como um produto estritamente objetivo, preciso e verossimilhante, uma vez que estes aspectos encontram-se imbricados com outros aspectos contraditórios resultantes do próprio fazer jornalístico.

Diferente da literatura em que a objetividade é colocada em suspensão através de um pacto entre o autor e o leitor, no jornalismo, a objetividade do texto é colocada como pressuposto básico para o acordo entre o jornalista e o leitor. Contudo o jogo que se opera entre o mundo texto e o mundo do leitor implica em uma intersubjetividade onde a objetividade pode ser suspensa e assim permitir a travessia do mundo real ultrapassado para o mundo dos sentidos produzidos.

\section{O jornalista: um observador capaz de co-construir a realidade.}

A conduta profissional sustenta o ponto de vista de que o trabalho jornalístico deve ser o resultado de um exame apurado da realidade, onde a habilidade do jornalista será valorizada à medida que este, ao se colocar em uma posição externa a essa realidade, dispõe da capacidade para manejar as ferramentas e as técnicas consagradas pela profissão. É possível inferir que, enquanto profissionais, os jornalistas se coloquem externos à realidade; contudo, como indivíduos pertencentes a uma sociedade definida em um tempo e um espaço

Comun. Inf., v. 6, n. 1, p.73-86, jan./jun. 2003 


\section{2}

específicos, se encontram imbricados pelos aspectos relativos a esse contexto.

Ao outorgar a possibilidade desse duplo papel, o jornalismo confere aos seus profissionais a sensação de realizar um trabalho de forma neutra abstraída de qualquer valor pessoal. Como aponta Traquina (1999), a noção básica que os jornalistas têm do seu próprio trabalho refere-se à atuação enquanto repórteres-refletores-indicadores de uma realidade objetiva "lá fora". Todavia, ao ampliar o foco da referida prática, torna-se evidente o contexto organizacional, institucional, social e pessoal pelo qual tal trabalho se encontra permeado.

Sob esse prisma, como parte integrante de um sistema, o jornalismo não pode ser entendido de forma isolada como o resultado de um olhar externo, objetivo, neutro e por isso verdadeiro. Baseado nos postulados descritos por Maturana (2001), onde a realidade inexiste independente do observador e tudo que é dito é dito por um observador, o trabalho do jornalista pode ser entendido como o resultado de uma distinção da realidade multiversa feita por um observador.

Considerar a realidade como multiversa implica em aceitar a capacidade do ser humano em construí-la através do domínio lingüístico. Neste sentido, o termo, utilizado por autores construtivistas e construcionistas, pressupõe uma objetividade entre parênteses capaz de aceitar múltiplas versões, ou seja, "tantos domínios da realidade quantos domínios de coerências operacionais sejam constituídos pelas operações de distinção dos observadores" (VASCONCELLOS, 2002: 141). Cabe ressaltar que aceitar a objetividade entre parênteses não significa substituí-la em prol da subjetividade; mas sim ao contrário do que fundamenta a ciência tradicional, que a acusa de relativismo e/ou solipsismo, compreendela como caminho explicativo onde o "observador não dispõe de bases operacionais para fazer qualquer declaração ou afirmação sobre objetos, entidades ou relações, como se esses existissem independentemente do que ele faz" (MATURANA, 1997: 250).

Sendo assim, a objetividade tão exaltada pelo positivismo como argumento não só necessário, mas suficiente para descrever a realidade de forma incontestável, uma vez inserida no novo paradigma da ciência, não pode mais ser garantida sob o argumento de referência ao real. A objetividade entre parênteses liberta a realidade de sua condição externa e, por conseguinte, do compromisso com a verdade, aqui entendida como a única verdade possível de ser apreendida e

Comun. Inf., v. 6, n. 1, p.73-86, jan./jun. 2003 
isenta de subjetividade, para então compreendê-la como o resultado de uma construção consensualmente compartilhada por uma comunidade de observadores e capaz de múltiplas verdades, cada qual estruturada através de diferentes narrativas. As narrativas, por sua vez, segundo Maturana (2001), permitem à linguagem construir a realidade, não como a origem de uma referência, mas como um modo de contínua transformação no devir do mundo lingüístico que o indivíduo constrói com os outros indivíduos.

Nestes termos, o jornalismo se apresenta como um importante propulsor para o processo de construção da realidade, uma vez que, ao distinguir os fatos possíveis de ser tornarem acontecimentos jornalísticos, o jornalista os hierarquiza oferecendo à sua comunidade de leitores a possibilidade de compartilhá-los e, por conseguinte, consensualmente construir a realidade na qual ambos se encontram inseridos. O jornal, ao funcionar como veículo de informação, produz junto ao leitor um efeito ritualístico capaz de organizar a experiência social em um determinado tempo e espaço. Contudo torna-se pertinente ressaltar que o processo de construção da realidade e o seu consequente efeito ritualístico não são resultados do trabalho exclusivo do jornalista, isso porque não se trata de outorgar onipotência ao profissional, mas sim inseri-lo em um processo circular do qual fazem parte de forma complementar tanto aspectos organizacionais da instituição como os aspectos individuais do leitor.

\section{O relato dos fatos transformando-se em estórias.}

O texto jornalístico ao ser entendido como espaço onde se instaura o jogo de intenções e expectativas de forma que o leitor responda criativamente à estratégia textual do autor contribui para conferir à notícia o status de estória. Tal atribuição, no entanto, encontra facilmente o repúdio por parte da maioria dos profissionais, os quais advogam em nome da verdade e da objetividade e, para tanto, são capazes de apresentar técnicas, normas e recursos estilísticos como justificativa de sua prática. Todavia argumentar que as notícias são estórias não significa atribuir juízo de valor, afirmar que estas são invenções mentirosas ou que resultam de uma prática profissional deturpada. Ao contrário, segundo Tuchman (1999), dizer que uma notícia é uma estória não é de modo algum rebaixá-la ou acusá-la de ser fictícia, mas sim ressaltar o fato de que a notícia, como todos os

Comun. Inf., v. 6, n. 1, p.73-86, jan./jun. 2003 
documentos públicos, consiste em uma realidade possuidora da sua própria validade interna.

Galgado na imparcialidade, no reflexo da realidade e na verdadeira representação, o jornalista esforça-se em consubstanciar a singularidade do seu trabalho em relação ao trabalho de um autor literário. Ao justificar-se através de dispositivos retóricos e estruturais como métodos de transmitir informações precisas, o jornalista tem como intuito salvaguardar o seu trabalho do risco de se caracterizar como uma obra de ficção. A notícia pode apresentar aspectos semelhantes aos de uma obra literária, inclusive indícios de ficcionalidade, contudo, torna-se prudente que o fictício não deva ser entendido aqui como "mentira, falsidade", mas sim com base nos postulados de Wolfgang Iser (1999) caracterizando-o como uma travessia de fronteiras entre os dois mundos, que sempre inclui o mundo que foi ultrapassado e o mundo alvo a que se visa.

Os relatos noticiosos, entendidos como narrativas culturalmente construídas, implicam em uma relação de coexistência entre fato e relato do fato. Isso porque o jornalista como observador só distingue o fato através do próprio relato do fato, de forma que o mesmo passe a existir a partir do momento em que o observador o constrói narrativamente. Como narrativa, as notícias estabelecem fronteiras artificiais, segundo Ricoeur (1994) construindo totalidades significativas a partir de acontecimentos dispersos. Nesse sentido, Bird e Dardenne (1999) ressaltam que, mais que considerar a exatidão dos fatos e a sua correspondência com uma realidade externa, é possível considerá-los como atributos da narrativa, como elementos numa ordenação humana dos mesmos; o que pode ser corroborado pelas palavras de Ricoeur (1994) ao acrescentar que o tempo torna-se humano na medida em que é articulado de um mas antes constrói o seu próprio mundo, da mesma forma, a notícia ao contrário do que advogam os cânones jornalísticos funcionam menos como refletoras de uma realidade externa e objetiva e mais como construtoras de uma realidade consensualmente compartilhada.

Inseridas em um processo ritualístico, narrativas mitológicas e notícias permitem de uma forma dinâmica o contar e o re-criar de modelos da experiência social. Neste sentido, o caráter ritualístico opera tanto em um nível pragmático do comportamento individual e coletivo quanto em um nível simbólico, seja individual ou coletivo. De acordo com Geertz (1973) apud BIRD e DARDENNE (1999: 266) enquanto

Comun. Inf., v. 6, n. 1, p.73-86, jan./jun. 2003 
sistema simbólico, o mito e as notícias atuam ambos como modelo de e para uma cultura. As notícias, como aspecto pragmático, relatam acontecimentos inusitados, inesperados, considerados desvios ou rupturas no cotidiano, no entanto, como aspecto cultural, transmitem acontecimentos familiares, cujos temas parecem repetir-se e embora se refiram a acontecimentos diferentes podem ser codificados em estruturas já percebidas e previstas.

Todavia reconhecer a implicação do jornalismo, enquanto construtor da realidade posterior e consensualmente compartilhada pelos leitores, e a sua capacidade de atuação seja a nível pragmático ou a nível simbólico na organização da experiência social, não significa outorgar ao mesmo um status privilegiado capaz de manipular a realidade, condicionar as diretrizes da conduta individual ou coletiva e controlar o processo cultural. Entendido sob esse prisma, o jornalismo consiste muito mais em um elemento constitutivo da cultura de uma sociedade capaz de funcionar de forma dinâmica organizando-a e mutuamente sendo por ela organizado.

\section{Abstract}

The following essay focus on meaning forgery through interaction between the reader and the news, which happens during the act of reading. News is no longer taken as the absolute truth upon an imparcial report, but as one of the possible distinctions of a multifaceted reality enviewed by the journalist which immerses the reader as an active part of the dealing and updating of the meanings in a process of shared building of social reality.

Key words: meaning forgery, co-building of social reality, journalistic narrative.

\section{Referências}

ECO, Umberto. Lector in fabula. 2a ed. São Paulo: Ed. Perspectiva S. A., 2002. FREY, Northrop. Anatomia da Crítica. Cultrix, 1973.

BIRD, Elizabeth S. \& DARDENNE, Robert W. Mito, registo e "estórias": explorando as qualidades narrativas das notícias. In: TRAQUINA, Nelson (org.). Jornalismo: Questões, Teorias e "Estórias". 2a ed. Lisboa: Ed. Vega, 1999, p.263-277.

ISER, Wolfgang. Teoria da Recepção: reação a uma circunstância histórica. In: ROCHA, João Cezar de Castro (org.). Teoria da Ficção: indagações à obra de Wolfgang Iser. Universidade do Estado do Rio de Janeiro. Colóquio (7.: 1996:

Comun. Inf., v. 6, n. 1, p.73-86, jan./jun. 2003 
RJ). Trad. Bluma Waddington Vilar, João de Castro Rocha. Rio de Janeiro: Ed. UERJ, 1999. p. 19-34.

, Wolfgang. O Fictício e o Imaginário. In: ROCHA, João Cezar de Castro (org.). Teoria da Ficção: indagações à obra de Wolfgang Iser. Universidade do Estado do Rio de Janeiro. Colóquio (7.: 1996: RJ). Trad. Bluma Waddington Vilar, João de Castro Rocha. Rio de Janeiro: Ed. UERJ, 1999. p. 63-78.

, Wolfgang. O Jogo. In: ROCHA, João Cezar de Castro (org.). Teoria da Ficção: indagações à obra de Wolfgang Iser. Universidade do Estado do Rio de Janeiro. Colóquio (7.: 1996: RJ). Trad. Bluma Waddington Vilar, João de Castro Rocha. Rio de Janeiro: Ed. UERJ, 1999. p. 105-116.

Manual de Redação Folha de S. Paulo. 5a ed. São Paulo: Publifolha, 2002. MATURANA, Humberto. A ontologia da realidade. Belo Horizonte: Ed. UFMG, 1997.

, Humberto. A árvore do conhecimento: as bases biológicas da compreensão humana. São Paulo: Palas Athenas, 2001.

MOUILLAUD, Maurice. A Informação ou a Parte da Sombra. In: PORTO, Sérgio Dayrell (org.) O Jornal: da forma ao sentido. 2a ed. Brasília: Editora Universidade de Brasília, 2002. p.37-48.

RICOEUR, Paul. Tempo e Narrativa - Tomo I. Campinas - SP: Ed. Papirus, 1994. RICOEUR, Paul. Tempo e Narrativa - Tomo III. Campinas - SP: Ed. Papirus, 1997.

TRAQUINA, Nelson. As Notícias. In: TRAQUINA, Nelson (org.) Jornalismo: Questões, Teorias e "Estórias". Lisboa: Ed. Vega, 1999. p.258-262.

TUCHMAN, Gaye. A Objectividade como Ritual Estratégico: uma análise das noções de Objetividade dos Jornalistas. In: TRAQUINA, Nelson (org.). Jornalismo: Questões, Teorias e "Estórias". 2a ed. Lisboa: Ed. Vega, 1999, p. $74-90$.

VASCONCELlOS, Maria José Esteves. Pensamento Sistêmico - o novo paradigma da ciência. Campinas - SP: Ed. Papirus, 2002.

Comun. Inf., v. 6, n. 1, p.73-86, jan./jun. 2003 